\title{
Globalization and Workers' Health
}

\author{
Ichiro KAWACHI ${ }^{1}$ \\ ${ }^{1}$ Harvard School of Public Health, 677 Huntington Ave, Boston, MA 01776, USA \\ Received July 1, 2008 and accepted July 11, 2008
}

\begin{abstract}
The global integration of economies worldwide has led to increased pressure for "labor flexibility". A notable aspect of this trend has been the rise in non-standard work arrangements, which include part-time work, temporary agency-based work, fixed-term contingent work, and independent contracting. Although non-standard work arrangements are convenient for employers, they are often associated with poor pay, absence of pension and health benefits, as well as lack of protection from unions and labor laws. Studies have begun to address the question of whether these "precarious" jobs pose a health hazard for workers. The challenge for causal inference is that precarious workers are likely to differ from non-precarious workers in a variety of characteristics that also influence health outcomes, i.e. there is confounding and selection bias. However, even after taking account of these biases - through propensity score-matched analysis - there is evidence to suggest that non-standard work may be damaging to workers' health. Policies modeled after the European Union's Directive on Part-Time Work may help to mitigate some of the health hazards associated with precarious work.
\end{abstract}

Key words: Globalization, Non-standard work, Propensity score matching

\section{The Changing Nature of Work in a Globalized Economy}

Globalization has delivered many benefits, such as increasing prosperity through trade, and the exchange of knowledge, information, and technology across borders. At the same time, globalization is associated with many challenges, including the demand for "labor flexibility" which has threatened the security of workers throughout the world ${ }^{1)}$. In a globalized economy, employers worldwide have been forced to contend with intensifying competition and increased pressures for cost-containment. Workers' jobs are constantly under threat of down-sizing, out-sourcing, and sub-contracting. In such an environment, labor markets throughout the industrialized world have witnessed a sharp increase in the prevalence of socalled "non-standard" types of jobs - also referred to as "precarious" employment, "contingent work", "flexible work arrangements", or "disposable work"2). In the United States, which has been a world leader in labor flexibility, non-standard work arrangements represent nearly one-third of the work force since the $1990 \mathrm{~s}^{3)}$. In the U.S. work force, non-standard workers include parttime workers $(20 \%)$, independent contractors $(7 \%)$, temporary help agency-based jobs $(2.5 \%)$, as well as fixed- term contract workers, which include on-call jobs such as substitute teachers and nurses (3\%). During the past decade, non-standard forms of work have also rapidly spread to other parts of the world. For example, both Japan and Korea have witnessed sharp increases in the prevalence of non-standard jobs since the economic crises of the late $1990 \mathrm{~s}^{4)}$.

\section{Nonstandard Employment — Is it Damaging to Workers' Health?}

Recent epidemiological research has begun to address the question: Is non-standard work damaging to the health of workers? On the one hand, non-standard work has some benefits, such as the ability of workers to control their schedules. Non-standard jobs are also convenient to employers, who can screen workers prior to hiring them permanently (thereby reducing training costs), and also allows companies to cut labor costs during slack times. On the other hand, there are a variety of reasons to believe that non-standard work arrangements are disadvantageous to workers. For example, non-standard jobs are often "bad" jobs, i.e. associated with poor pay, and often lack health insurance and pension benefits. Non-standard jobs also lack protection from unions and labor laws, and are 
associated with a high degree of job insecurity ${ }^{3)}$.

Although a growing number of studies have suggested that non-standard work is associated with deleterious impacts on workers' health ${ }^{5-7)}$, causal inference has remained challenging because of the obvious selection of different types of workers into different types of jobs. Thus, for example, people engaged in non-standard forms of work are likely to have a lower level of educational attainment compared to "standard" workers. They are also less likely to be married, and more likely to have health problems prior to entering the work-force. Since many of these selection factors also influence health status, a comparison of the health outcomes of non-standard versus standard workers is likely to be biased unless confounding factors are carefully controlled.

In an attempt to overcome this causal inference problem, we recently investigated the potential impact of nonstandard employment on workers' health by performing a propensity-score matched analysis, using prospective data from the 4th wave of the Korean Labor and Income Panel (KLIP) Study, 20018). The dataset included 1,991 male and 1,378 female Korean workers, with information on employment type and self-rated health status (i.e. the single-item question: "How would you rate your overall health?", where we dichotomized the responses to "poor" vs. "good", "very good", or "excellent").

Non-standard employment is this study was defined as workers engaged in part-time work, daily or temporary work, as well as fixed-term contract ("contingent") work. Together, we labeled these arrangements as "precarious" work.

The essence of the propensity-score approach is to match individuals on their "propensity" to become exposed (i.e. to become a precarious worker). Formally, the propensity score (PS) is defined as:

$$
\operatorname{PS}=\operatorname{Prob}(\mathrm{E}=1 \mid \mathrm{Zi})
$$

which is the conditional probability of becoming exposed $(E=1)$, given all of the workers' observed covariates $(\mathrm{Zi})$, which are used to balance potential confounding variables across the comparison groups (precarious vs. non-precarious workers), and hence reduce bias: Logistic models were used to calculate the PS for each worker, using information on age, educational attainment, household income, marital status, occupation, type of industry, as well as prior health status and prior occupational status.

Once propensity scores (ranging from 0.0 to 1.0 ) were calculated for each worker, each precarious worker was then matched with up to three non-precarious workers through an algorithm in which matches were made within a propensity score range ("caliper width") of 0.1 . The

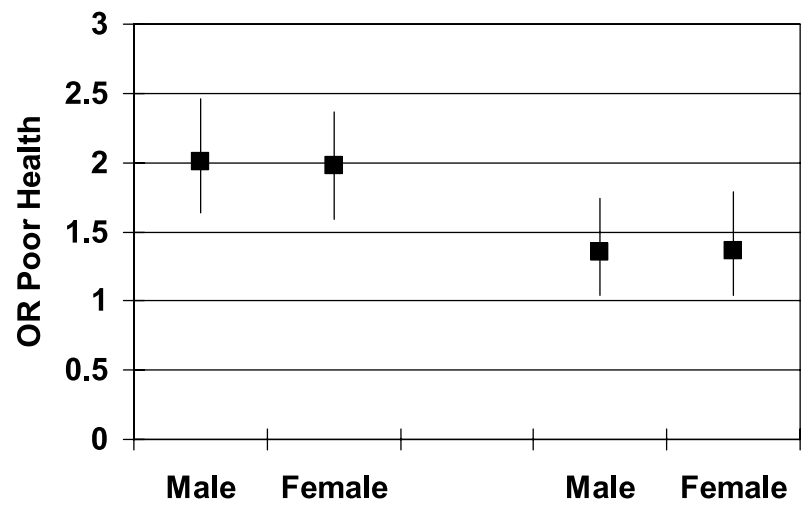

Fig. 1. Odds ratios (and $95 \%$ confidence intervals) of reporting poor health among precarious workers (compared to non-precarious workers) in the 4th wave of the Korean Labor and Income Panel Survey, 2001.

Before propensity score-matching (left hand pair) and after propensity score matching (right hand pair) — see text for further explanation.

goal of matching is to compare the health outcomes of workers who resemble each other in their propensity to become a precarious worker, i.e. even if someone is a non-precarious worker, at least they had the background characteristics where they could have been a precarious worker.

Figure 1 illustrates the odds ratios of poor self-rated health status among precarious workers (compared to nonprecarious workers) with and without the propensity score matching procedure. The unmatched analyses indicate that precarious workers have double the odds of reporting poor health compared to non-precarious workers. However, after the matching procedure, the odds ratios are reduced closer to 1.5 (although still statistically significantly elevated). In summary, precarious employment is associated with increased risk of poor health even after taking account of confounding variables and the selection of workers with different background characteristics into precarious employment.

\section{The Future of "Decent Work"}

What are the policy implications of studies that suggest a link between precarious employment and poor health outcomes? As globalization increases the pressure to adopt non-standard forms of employment, countries should consider introducing legislation modeled after the European Union (EU) Directive on Part-Time Work. The EU Directive, adopted in 1997, has sought to eliminate discrimination against part-time workers through a mixture of legislation and collective agreements that address pay equity, pension benefits, training and promotion opportunities, as well as bargaining rights ${ }^{9}$. 
Globalization needs not be associated with an inevitable decline in the quality of work for millions of workers. "Decent work" can be an achievable reality. Overall, it is not the global integration of economies per se which is a threat to workers' health, but rather the ways in which the consequences of globalization are managed - or not.

\section{References}

1) Hogstedt C, Wegman DH, Kjellstrom T (2007) The consequences of economic globalization on working conditions, labor relations, and workers' health. In: Globalization and health, Kawachi I and Wamala S (Eds.), 138-57, Oxford University Press, New York.

2) Kalleberg AL (2000) Nonstandard employment relations: part-time, temporary and contract work. Annu Rev Sociol 26, 341-65.

3) Kalleberg AL, Reskin BF, Hudson K (2000) Bad jobs in America: standard and nonstandard employment relations and job quality in the United States. Am Sociol Rev 65, 256-78.
4) Tachibanaki $\mathrm{T}$ (2006) Unequal society: what is the problem?, Iwanami Shoten, Tokyo (in Japanese).

5) Benach J, Benavides FG, Platt S, Diez-Roux A, Muntaner C (2000) The health-damaging potential of new types of flexible employment: a challenge for public health researchers. Am J Public Health 90, 1316-7.

6) Benach J, Gimeno D, Benavides FG, Martinez JM, Torne MD (2004) Types of employment and health in the European Union —Changes from 1995 to 2000. Eur J Public Health 14, 314-21.

7) Benavides FG, Benach J, Diez-Roux AV, Roman C (2000) How do types of employment relate to health indicators? Findings from the Second European Survey on Working Conditions. J Epidemiol Comm Health 54, 494-501.

8) Kim MH, Kim C-Y, Park J-K, Kawachi I (2008) Is precarious employment damaging to health? Results of propensity score matching methods, using longitudinal data in Korea. Soc Sci Med (in press).

9) Europa (2004) The Part-Time Work Directive. http://europa.eu/scadplus/leg/en/cha/c10416.htm. Accessed July 1, 2008. 